\title{
OS PRIMEIROS PASSOS DE UM PROGRAMA DE ERGONOMIA NA EMPRESA: DUAS EXPERIÊNCIAS DISTINTAS
}

\section{FIRSTS STEPS OF A PROGRAMME OF ERGONOMICS IN COMPANIES: TWO SINGLE EXPERIECES}

\author{
Marcelo M. Soares ${ }^{1}$; Germannya D’Garcia de Araújo Silva ${ }^{1}$; \\ Débora T. F. Ramos ${ }^{1}$; Glenda G. Cabral ${ }^{1}$; Juliana Leal da Cruz \\ ${ }^{1}$ ERGOLAB - Laboratório de Ergonomia e Usabilidade de Produtos, Sistemas e \\ Produção | Departamento de Design | Universidade Federal de Pernambuco \\ Cidade Universitária / Recife-PE / 50.670 - 420 \\ marcelo2@nlink.com.br; germannya@yahoo.com.br; \\ dt_ferro@ibest.com.br; glendagcabral@yahoo.com.br
}

\begin{abstract}
Resumo
O presente trabalho tem como objetivo apresentar uma análise comparativa dos primeiros passos da gestão do programa de Ergonomia em duas empresas de grande porte no Estado de Pernambuco. Para ambos os casos foi utilizado um método de ergonomia participativa que envolveu a criação de um Comitê de Ergonomia (COERGO) responsável pela implementação de ações ergonômicas em cada empresa. Esta estratégia permitiu uma maior participação dos trabalhadores na identificação e solução dos problemas ergonômicos. A experiência teve um resultado positivo ao demonstrou o envolvimento dos trabalhadores nas soluções adotadas $e$ justificou a necessidade de se adequar o método ergonômico as características peculiares de cada empresa.
\end{abstract}

Palavras Chaves: Programa de ergonomia; comitê de ergonomia; análise do trabalho

\section{Introdução}

De acordo com Silveira (2004), um programa é um projeto escrito minucioso que dá a conhecer os pormenores de um plano. Os programas de ergonomia não são planos isolados. Eles só têm sentido quando fazem parte da política empresarial para segurança e saúde nos ambientes de trabalho; ou seja, fazem parte do plano estratégico da empresa.

Um programa de ergonomia é, também, a melhor solução para organizar ações gerenciais, porque captam a realidade complexa dos ambientes de trabalho em pequenas partes, tornando-as compreensíveis, planejáveis e manejáveis. São soluções técnicas cuja implementação depende de como as pessoas que compõem a organização encaram o problema de forma organizada, ágil e prática. 
As principais vantagens na implantação de programas de ergonomia na empresa, segundo Silveira (o.p.), são:

1. Ações mais consistentes, aumentando as chances de parcerias e envolvimento dos beneficiários, gerando impacto;

2. Pessoas mobilizadas a participarem de ações promovidas pela empresa, promovendo parcerias internas;

3. Ações de melhorias nas condições de trabalho com melhores resultados e menores custos gerando confiança, por parte da organização e seus colaboradores, gerando sentimento de legitimidade e credibilidade;

4. Promoção progressiva da reflexão coletiva sobre a experiência, gerando produção de conhecimento relevante a outros programas dentro da empresa;

5. Promoção de espaço para negociação e expressão dos agentes, por estar calcado sobre metas, objetivos e critérios de avaliação, gerando negociação de interesses.

Desta forma, para fortalecer as mobilizações geradas pelas parcerias internas, o autor apresenta, como ação inicial, a formação de um comitê de ergonomia, entendendo os trabalhadores como os principais responsáveis pelas mudanças. Desta forma, antes mesmo do início oficial do programa, devem ser realizadas reuniões com o contratante para a definição deste comitê, organizado no formato de Grupos de Ação. Recomenda-se que essa composição integre diversos setores e equipes de trabalho da empresa, desde o nível estratégico, ao operacional.

A idéia de compor o COERGO através de grupos de ação é a atuação específica de cada membro dentro de um plano devidamente estruturado. A tabela 1, a seguir, apresenta a estrutura de composição do COERGO, com o conceito e o objetivo de cada grupo. Já a Figura 1, apresenta um esquema para a modelagem (estrutura operacional) de um programa de ergonomia na empresa.

A participação do COERGO dentro do processo de intervenção ergonomizadora se faz necessária, desde o reconhecimento do problema até a validação dos resultados.

Uma vez identificada a não existência do Comitê de Ergonomia na empresa, faz-se necessária a composição do mesmo, seguindo-se o procedimento: [i] identificar e selecionar trabalhadores, de preferência voluntários, de vários setores para representação da maioria dos empregados da empresa; [ii] ministrar treinamentos teóricos e práticos sobre assuntos básicos da ergonomia, a fim de nivelar o discurso entre os membros e promover a integração dos setores; [iii] estabelecer o cronograma de reuniões sistemáticas para negociação, discussão e apresentação das recomendações propostas; [iv] definir estratégias de ação para execução das recomendações e por fim; [v] gerar ações para comunicar as ações do programa junto aos outros empregados. Todavia, observou-se nos estudos de caso aqui ilustrados que, em função da organização sindical e da própria estrutura organizacional das empresas, a formação dos comitês e a condução das atividades podem 
acontecer de maneiras diferentes.

Tabela 1 - Grupos de ação do COERGO

Figura 1 - Estrutura operacional de um programa de ergonomia

na empresa (Silveira, 2004).

\begin{tabular}{ll}
\hline Grupos & Ação \\
\hline GA1 & $\begin{array}{l}\text { Grupo de Interesse (GI) e Equipe de } \\
\text { Ergonomia }\end{array}$ \\
GA2 & $\begin{array}{l}\text { Grupo de Formação em Ergonomia, } \\
\text { conceito, métodos e técnicas, com a } \\
\text { responsabilidade da ação } \\
\text { ergonômica na empresa. }\end{array}$ \\
GA3 & $\begin{array}{l}\text { Grupo Foco - operadores alvo da } \\
\text { pesquisa }\end{array}$ \\
GA4 & $\begin{array}{l}\text { Grupo de Acompanhamento - } \\
\text { autoridades técnicas } \\
\text { GA5 }\end{array}$ \\
$\begin{array}{l}\text { Grupo de Suporte - poder de } \\
\text { decisão na organização para } \\
\text { mudanças }\end{array}$ \\
\hline
\end{tabular}

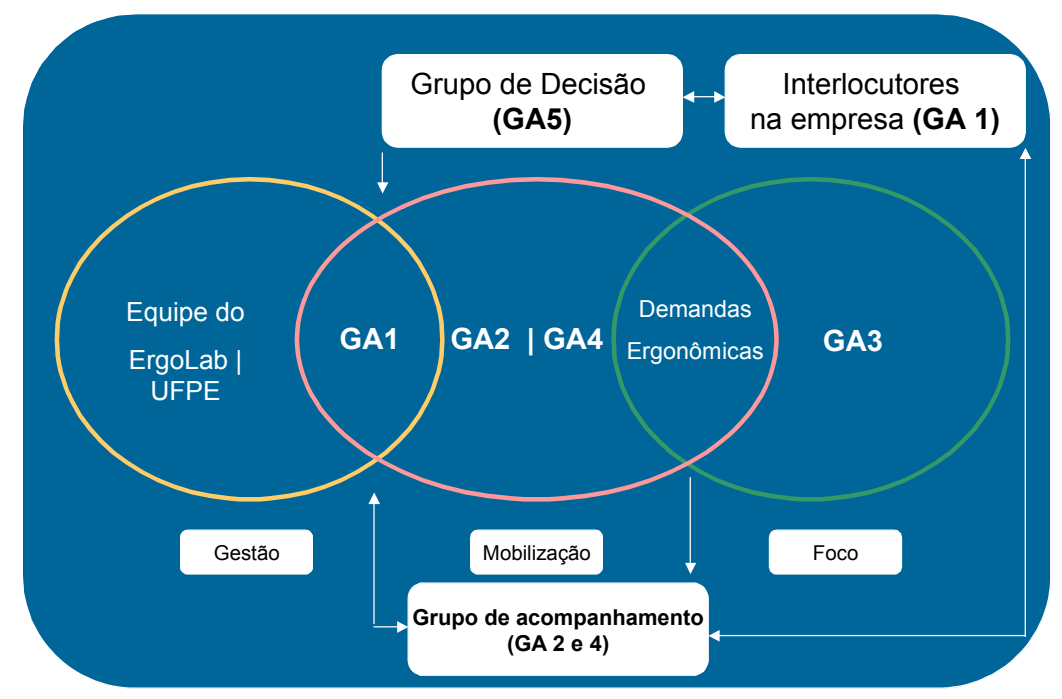

Como recortes da pesquisa, serão apresentados, a seguir, dois casos diferentes de composição e atuação inicial do COERGO em empresas distintas. O primeiro, ocorrido numa indústria de engarrafamento de bebidas, denominada neste artigo como "Empresa A", e o segundo, numa empresa de transformação do setor de embalagem de alimentos, denominada neste artigo como "Empresa B", ambas iniciando um Programa de Ergonomia.

\section{Composição e primeiras ações do COERGO na "Empresa A"}

A "Empresa A" é composta de uma unidade administrativa e outra produtiva, classificada como Indústria de Engarrafamento de Bebidas. Funciona em três turnos de trabalho sendo, o último, destinado à manutenção da linha de produção e carregamento de caminhões para clientes. A fábrica funciona em horário de turno para os setores de produção e logística (manhã: das 06h20min às 13h40min / tarde: das $13 \mathrm{~h} 40 \mathrm{~min}$ às $22 \mathrm{~h} 20 \mathrm{~min}$ de segunda a sábado). Já o escritório funciona em horário administrativo (das 07h30min às 17h30min de segunda a sexta). Todos os funcionários da empresa trabalham em horário fixo, sem escala. A maior parte das atividades da fábrica requer atuação direta da mão de obra, que tem como formação básica o ensino médio.

Iniciado em 2003, o estudo ergonômico dos postos de trabalho da empresa teve, em 2005, sua evolução para um Programa de Ergonomia. Durante a fase inicial do programa, foram estruturadas etapas estratégicas, as quais permitiram a sua execução de forma consistente e organizada. A primeira delas consistiu na composição do COERGO, criado para, num primeiro momento, auxiliar na coordenação e mobilização interna dos funcionários, no que diz respeito à 
intervenção ergonomizadora. O segundo objetivo seria fazer com que esse COERGO, uma vez treinado, assumisse a condução dos trabalhos sob a supervisão de um consultor.

O COERGO, nesta empresa, foi composto antes mesmo do início oficial do programa. Foram realizadas algumas reuniões com a alta gerência, onde se definiu a estrutura física e organizacional do comitê. Durante esta etapa, um dos membros do comitê apresentou uma proposta para a identidade visual que, rapidamente, tornou-se a mascote do programa de ergonomia. Hoje, a imagem é utilizada nas campanhas promocionais de ergonomia na empresa.

Cumpre salientar que, em decorrência da atuação radical e repressiva do sindicato de bebidas de Pernambuco, optou-se em constituir o comitê apenas com membros da administração da empresa. Esta decisão deu-se pelo receio que as informações geradas no processo de intervenção sobre os problemas ergonômicos da empresa "vazassem" e fossem indevidamente usadas pelos membros do sindicato. $\mathrm{O}$ acesso à documentação referente ao programa de ergonomia no sistema ficou assim autorizado apenas aos membros dos Grupos de Ação 01, 02, 04 e 05. A tabela 2, a seguir, apresenta a composição do COERGO da "Empresa A".

Tabela 2 - Grupos de ação do COERGO - "Empresa A"

\begin{tabular}{lll}
\hline Grupos & Ação & Agentes \\
\hline GA1 & Grupo de Interesse (GI) e Consultoria externa & $\begin{array}{l}\text { Equipe do ErgoLab; Coordenação de RH; Médico do } \\
\text { Trabalho; }\end{array}$ \\
GA2 & $\begin{array}{l}\text { Grupo de Formação em Ergonomia, conceito, } \\
\text { métodos e técnicas, com a responsabilidade da ação } \\
\text { ergonômica na empresa. }\end{array}$ & $\begin{array}{l}\text { Médico do Trabalho, Técnico em Segurança do } \\
\text { Trabalho; Equipe de Recursos Humanos; } \\
\text { Coordenadores das áreas de Produção; Logística, } \\
\text { Padronização; Qualidade; Engenharia e Manutenção } \\
\text { Todos os trabalhadores do chão de fábrica e escritório }\end{array}$ \\
GA3 & Grupo Foco - operadores alvo da pesquisa & $\begin{array}{l}\text { Encarregados das áreas de produção e logística } \\
\text { GA4 }\end{array}$ \\
$\begin{array}{l}\text { Grupo de Acompanhamento - autoridades técnicas } \\
\text { Grupo de Suporte - poder de decisão na organização }\end{array}$ & Gerente da planta NE \\
\hline
\end{tabular}

Os integrantes do Grupo de Ação 03 participaram intensamente das demandas ergonômicas, mas apenas podem acessar os documentos disponibilizados na pasta virtual do programa aberta ao público, contendo as informações já validadas pelos grupos, cronogramas de execução das recomendações e as cópias dos treinamentos ministrados.

Como primeira ação do comitê, foi planejada a atividade do Lançamento do Programa: um evento com duração de três dias com diversas atividades durante o período:

1. Abertura - Palestra Magna sobre como funcionará o programa de ergonomia na empresa, realizada para um público com mais de 150 funcionários da empresa ocorrida no galpão da fábrica; 
2. Atividades sistemáticas - Sessões programadas de palestras, proferidas pelos membros do ErgoLab, com o tema "A Ergonomia no Dia a Dia“. A palestra foi proferida para as cinco turmas, durante toda a programação da empresa, contemplando $100 \%$ dos colaboradores, incluindo os terceirizados. Durante as palestras, foi solicitado o preenchimento de uma enquete para identificação dos pontos positivos e negativos de cada setor. O objetivo era captar, de forma espontânea, todas as insatisfações dos colaboradores.

4. Atividades pontuais 1 - Exibição do filme "Tempos Modernos", com Charles Charplin, no refeitório da empresa, para desertar o espírito crítico da ergonomia entre os empregados;

4. Atividade pontual 2 - Concurso de frases que traduzissem o conceito da ergonomia para a empresa, lançado no dia da abertura, com prazo até o último dia do evento.

5. Encerramento - Entrega solene da premiação para as melhores frases do concurso e apresentação oficial do COERGO para todos os empregados.

Na seqüência, como segunda fase do Lançamento do Programa, ocorreram os treinamentos do COERGO. O objetivo foi proporcionar uma formação mais intensificada em ergonomia aos membros dos grupos GA2 e GA4. A tabela 3, apresenta a programação de aulas do comitê.

Tabela 3 - Programação de treinamentos do COERGO da "Empresa A".

\begin{tabular}{clll}
\hline \multicolumn{1}{c}{ Ações } & \multicolumn{1}{c}{ Conteúdo } & Duração & \multicolumn{1}{c}{ Técnicas } \\
\hline \multirow{2}{*}{ Treinamento 1 } & Origem da Ergonomia & $8 \mathrm{~h}$ & \\
& $\begin{array}{c}\text { Métodos e Técnicas em Ergonomia 1 } \\
\text { Programa de Ergonomia nas empresas }\end{array}$ & $8 \mathrm{~h}$ & Aulas expositivas e atividades práticas em sala \\
Treinamento 2 & Perfil e voz do usuário & $10 \mathrm{~h}$ & $\begin{array}{l}\text { Aulas expositivas e atividades práticas em sala } \\
\text { Definição das Ferramentas de análise }\end{array}$ \\
Treinamento 3 & $\begin{array}{l}\text { Princípios de Biomecânica e } \\
\text { Antropometria }\end{array}$ & $10 \mathrm{~h}$ & Aulas expositivas e atividades práticas em sala \\
Treinamento 4 & Métodos e Técnicas em Ergonomia 2 & $12 \mathrm{~h}$ & Aulas expositivas e atividades práticas em sala \\
\hline
\end{tabular}

Todas as aulas ocorreram durante o horário de trabalho, em duas semanas consecutivas do mês de março e mais duas semanas do mês de maio de 2005. Em paralelo aos treinamentos, a equipe do ErgoLab, em parceria com o COERGO, iniciou as atividades de Exploração da Demanda.

Uma vez que a primeira análise ergonômica da empresa ocorreu em dezembro de 2003, fezse necessário uma re-análise das condições de saúde e segurança dos colaboradores, visando comparar a situação passada com a situação atual. Para a condução desta re-análise dos problemas, tomou-se como base o primeiro Relatório de Apreciação Ergonômica, finalizado em 2003, e elaborou-se um check-list baseado nos dados da Problematização. O resultado do check- list aplicado pelo COERGO, em campo, definiu quais os três postos prioritários para a intervenção.

Com a perspectiva de aprendizado, inicialmente, o COERGO acompanhou a equipe de ergonomia 
na análise do primeiro posto de trabalho - a plataforma. Em seguida, depois de concluída a primeira análise, bem como as propostas e estratégias de ação, os integrantes do COERGO assumiram a condução da segunda e da terceira análise, sendo supervisionados pela equipe de ergonomia para suporte técnico adequado.

Dando continuidade ao programa de ergonomia, após a finalização do segundo relatório, em junho de 2005, foi iniciada a fase de implementação das recomendações para o primeiro posto - a plataforma. Para tanto, foram criados grupos específicos de trabalho (físico e organizacional), mesclando os representantes dos grupos de ação GA1, GA2 e GA4. Esses grupos de trabalho possuíam, como meta, implementar as demandas do posto de trabalho da plataforma.

- Grupo Físico - dirigido para as recomendações de ordem dimensional e mudanças físicas do posto;

- Grupo Cognitivo/Organizacional - dirigido para as recomendações de gestão de pessoas e procedimentos de trabalho.

Todavia, durante o início da segunda etapa do programa (análise do posto do visor), percebeu-se a necessidade de subdividir ainda mais esses dois grupos de trabalho: Grupo de Trabalho da Plataforma e Grupo de Trabalho do Visor. O primeiro, responsável por implementar as recomendações de ordem física, cognitiva e organizacional orientadas para o posto da plataforma e o segundo, responsável por conduzir a análise e diagnóstico do posto do visor. Esses grupos passaram a fazer reuniões sistemáticas mensais, de acordo com a demanda, sendo convocado pelo comunicador oficial do programa - o técnico de segurança da empresa.

Cumpre salientar que todas as recomendações sob os aspectos físico, cognitivo e organizacional dos postos de trabalho, depois de validadas pelo GA3, foram estruturadas em formato de plano de ação a partir da ferramenta da qualidade 5 w2h. Este plano de ação vem sendo acompanhado pelos grupos da plataforma e do visor, sistematicamente, até a validação das propostas.

\section{Composição e primeiras ações do COERGO na "Empresa B"}

O outro caso de composição do COERGO deu-se numa metalúrgica e siderúrgica, voltada para o setor de embalagens de produtos alimentícios, composta por uma unidade administrativa e duas unidades produtivas, localizadas em uma mesma planta, sendo, as últimas, o foco inicial do Programa de Ergonomia. As unidades produtivas são compostas por duas fábricas bastante distintas tanto no que se refere ao sistema de manufatura quanto às atividades desempenhadas pelos trabalhadores. Enquanto, na fábrica 1,a maior parte das atividades requer a ação direta dos operadores de produção alimentando as máquinas com insumos, na fábrica 2 os técnicos de 
produção trabalham solucionando os problemas num processo totalmente automatizado.

A fábrica 1 é formada, principalmente, por operadores de produção, cuja formação é o ensino médio. A função destes operadores é manter o andamento da linha de produção, atendendo às demandas de entrada e saída das máquinas. Pode-se dizer que é um trabalho bastante mecânico e predominantemente repetitivo. A fábrica 2, por sua vez, é totalmente automatizada. Os funcionários possuem formação técnica e/ou universitária e a função é manter a linha de produção em funcionamento, mantendo o mínimo de contato com o produto, a não ser em situações excepcionais.

Em ambas as fábricas, predomina o mesmo sistema de escala de turnos. Ambas funcionam 24 horas, mantendo 04 turmas $[\mathrm{A}, \mathrm{B}, \mathrm{C}$ e D] trabalhando num regime de oito horas diárias, intercaladas por folgas. Deste modo, enquanto três turmas trabalham, uma desfruta de folga. A tabela 4, abaixo, indica o ciclo da escala de trabalho. Cada espaço sombreado corresponde a um dia de trabalho no turno da manhã [das $07 \mathrm{~h} 00 \mathrm{~min}$ às $15 \mathrm{~h} 00 \mathrm{~min}$ ], tarde [das $15 \mathrm{~h} 00 \mathrm{~min}$ às $23 \mathrm{~h} 00 \mathrm{~min}$ ] ou noite [das $23 \mathrm{~h} 00 \mathrm{~min}$ às $07 \mathrm{~h} 00 \mathrm{~min}$ ] ou a um dia de folga.

Tabela 4: Ciclo da escala de trabalho dos funcionários das fábricas da empresa 02.

\begin{tabular}{r||l|l|l|l|l|l|l|l|l|l|l|l|l|l|l|l|l|l|l|l|l|l|l|l} 
Manhã & 1 & 2 & 3 & 4 & 5 & 6 & & & & & & & & & & & & & & & & & \\
\hline \hline Tarde & & & & & & & & 1 & 2 & 3 & & & & & & & 1 & 2 & 3 & & & & \\
\hline \hline Noite & & & & & & & & & & & 1 & 2 & 3 & & & & & & & 1 & 2 & 3 & \\
\hline \hline Folga & & & & & & 1 & & & & & & & 1 & 2 & 3 & & & & & & 1 & 2
\end{tabular}

Da mesma forma que a "Empresa A", o processo de intervenção ergonômica teve início em 2002, e recomeçou no segundo semestre do ano de 2005, com o Programa de Ergonomia da empresa. Depois de firmado o contrato entre o Ergolab e a empresa em questão, passou-se a discutir, junto ao EHS [Departamento de Engenharia, Saúde e Segurança], como se daria a formação do COERGO.

Um dos aspectos relevantes à formação do COERGO nesta empresa diz respeito à política de Saúde, Higiene e Segurança vigente na mesma. Desde as primeiras reuniões, a gerência geral afirma que hierarquia é o fator menos importante quando se trata de Segurança e, de igual modo, de aspectos relacionados à Ergonomia.

Antes da composição oficial do COERGO, ocorreram apresentações em todas as turmas de trabalho, incluindo o setor administrativo, durante o intervalo de troca de turno, cumprindo o papel da etapa de lançamento do programa de ergonomia na empresa.

Embora, a princípio, tenha-se cogitado a implementação do COERGO envolvendo funcionários de ambas as fábricas e de todas as turmas, observou-se que isto seria inviável, tendo em vista a escala de trabalho desses funcionários, bem como as limitações contratuais de tempo da equipe de ergonomia junto à empresa. Sendo assim, optou-se pelo envolvimento inicial de uma das 
turmas, que serviria de agente multiplicador para as demais. Conforme sugestão do EHS, que considerou como critérios coesão e motivação, a turma $\mathrm{C}$ foi indicada para constituir o COERGO.

Uma reunião com os técnicos e operadores da turma $\mathrm{C}$ de ambas as fábricas serviu para apresentar o PROERGO e definir que funcionários participariam do COERGO, isto é, quem seriam os ergoagentes. Na fábrica 1, devido à grande quantidade de funcionários, os ergoagentes foram escolhidos por votação. Sendo que, para cada posto da fábrica, deveria haver um representante. Já na fábrica 2, os ergoagentes se dispuseram voluntariamente e, em acordo com os demais componentes da turma, foram integrados à equipe do COERGO.

Deste modo, o COERGO passou a ser constituído por um supervisor e 10 operadores da fábrica 1, mais 1 supervisor e cinco técnicos da fábrica 2, todos compondo o que seriam o GA2 e GA4. Compondo o GA1, foram indicadas a equipe do EHS e a consultoria externa - o Ergolab -; como GA3, todos os demais funcionários das fábricas e, como GA5, o gerente geral da unidade.

Seguindo o planejamento de atividades do programa, foram conduzidos treinamentos para o COERGO a partir de Outubro de 2005. Tais treinamentos envolveram os Grupos de Ação GA2/GA4 com o objetivo de proporcionar uma formação mais intensificada de ergonomia aos seus membros. Os treinamentos para os Grupos de Ação GA2 e GA4 ocorreram durante as folgas triplas da Turma C, com carga horária reduzida, em função do esquema da escala de trabalho.

Os integrantes do COERGO, a partir dos treinamentos de ergonomia, realizaram um levantamento dos principais problemas ergonômicos em cada uma das fábricas e hierarquizaram quais os setores que necessitam de uma intervenção imediata. Essa etapa é denominada Exploração da demanda, uma fase exploratória dos problemas. Como resultado desta primeira etapa, temos que os setores das máquinas Stolle, na fábrica 1, e Bodymaker, na fábrica 2 foram os primeiros postos a receberem a intervenção ergonômica na empresa.

O estudo ergonômico dos postos de trabalho ainda está em andamento. Entretanto, até o momento, algumas ações propostas pelo COERGO e outras que fazem parte do modelo de interveção já apresentaram resultados positivos.

\section{Ação 1}

O plano de ação gerado em 2002, referente à primeira análise ergonômica na fábrica 1, foi retomado pelo COERGO e algumas propostas foram encaminhadas para execução;

\section{Ação 2}

Foi realizada uma investigação nas instalações das fábricas para identificar quais os produtos químicos utilizados atualmente na produção e se as Fichas de Informações de Segurança de Produtos Químicos (MSDS) correspondentes estão sendo utilizadas pelos trabalhadores durante o exercício do trabalho. Como resultado desta ação, observou-se uma incoerência com o procedimento padrão. Existia um número alto de MSDS obsoletas e alguns produtos químicos sem 
a referida ficha de segurança. De posse do relatório, o setor de EHS tomou algumas ações de melhoria. Dentre elas: retirar do sistema as MSDS's obsoletas, cumprindo um item da ISO9000; manter na fábrica só as MSDS's utilizadas; treinar todos os funcionários para a utilização correta do documento;

\section{Ação 3}

Foi realizado um estudo pela equipe do ErgoLab, em parceria com o setor médico da empresa, sobre os registros das ocorrências (queixas) no ambulatório. Estes registros foram organizados em planilhas para auxiliar a análise. Os dados obtidos foram referentes ao período de um ano e foram classificados em 13 categorias pelo médico da empresa: cefaléia; queixas gastrointestinais; sintomas gerais, como mal-estar, moleza no corpo; queixas do aparelho respiratório; queixas do aparelho osteomuscular; irritação ocular; ferimentos, cortes e queimaduras; odontalgia; queixas do genitounrinária; aferição de pressão arterial; queixas do aparelho auditivo; curativos e outros, p. ex. furúnculo, picada de abelha, etc..

Todos esses registros ambulatoriais foram tratados com base nos seguintes critérios: [i] por turma; [ii] por trimestre; [iii] por queixas; [iv] por período do mês e [v] por horário de trabalho; com o objetivo de discutir e investigar, junto à gerência das fábricas, as possíveis causas dos problemas encontrados.

Os setores de EHS e RH, a partir das informações geradas, tomou as seguintes decisões: gerar informações efetivas dos dados registrados pelo ambulatório médico da empresa, através de tabelas de sumarização dos dados por período, por turma e por queixa; mudar o procedimento de atendimento das enfermeiras, posicionamento mais ativo e investigador das causas das queixas; fazer cruzamentos (associações) com a questão do absenteísmo na empresa; gerar item de KPI (controle) específico para doenças;

\section{Ação 4}

Foi conduzida a etapa de Aprofundamento das Hipóteses, com a técnica do Formulário (questionario + entrevista) com o objetivo de montar um perfil dos empregados da empresa e obter informações sobre as suas condições físicas, psicológicas, além das suas opiniões sobre os equipamentos e o ambiente de trabalho. A estratificação da amostra garantiu um índice de confiabilidade de $95 \%$ [p=0,05] para a pesquisa. Dois softwares foram usados para o tratamento dos dados: para a geração do banco de dados, utilizou-se o Excel versão 2000 e para a tabulação e análise dos dados, foi utilizado o SPSS [Statistical Package for Social Sciences], versão 11.0.

Para as variáveis quantitativas [que podem ser medidas numericamente], realizou-se estatísticas descritivas, como média e desvio padrão, para cada variável. Para as variáveis qualitativas [que não podem ser medidas numericamente], as respostas foram agrupadas por afinidade, ou seja, são consideradas componentes de um mesmo grupo de demandas, realizando um 
agrupamento por construto. Os reagrupamentos seguiram a definição de construto Ambiental; Biomecânico; Cognitivo; Organizacional; de Risco e ainda Empresa.

As respostas subjetivas foram transformadas em Plano de Ação, a partir da ferramenta da qualidade $5 \mathrm{w} 2 \mathrm{~h}$, na forma de sugestões verbais, recomendações e mudanças para o ambiente de trabalho. Esta ferramenta servirá como suporte para acompanhamento do projeto e será útil para o planejamento, pois identifica as diversas variáveis do projeto, atribuindo responsabilidades, definindo formas de intervenção, tempo e custo, etc.

Assim como na "Empresa A", o COERGO da "Empresa B" realizou reuinões sistemáticas para negociação e discussão dos problemas. Destas reuniões, pequenos grupos autônomos foram criados para dar andamento às demandas ergonômicas identificadas pelo GA3, dentre elas: propor mudança na escala de trabalho de ambas as fábricas; viabilizar a estrutura da ginástica laboral assitida por um profissional habilitado nas fábricas; integrar mais as outras turmas através de atividades lúdicas e campanhas educativas que envolvam o tema ergonomia. Atualmente, existe na “Empresa B” um concurso para criação da identidade visual do programa de ergonomia, aberto à participação dos funcionários. Além disso, foi instituido o minuto da ergonomia, onde representante do COERGO apresentam em 5 minutos, durante as reuniões de produção, temas simples, mas relevantes ao adequado desempenho das atividades de trabalho.

\section{Conclusão}

A viabilização de recursos financeiros pelas empresas para a realização de uma intervenção ergonomizadora nem sempre é uma realidade. Ainda mais quando se trata de uma situação como a formação de um Comitê de Ergonomia. Conforme abordado nos tópicos anteriores, este é um processo mais lento, que certamente dura mais tempo que uma intervenção feita apenas por ergonomistas.

Os estudos apresentados ainda estão em andamento. Sabe-se, inclusive, que algumas ações sugeridas levarão certo tempo para serem executadas. Entretanto, é importante deixar claro que o objetivo da metodologia aplicada nestas empresas, não é apenas intervir projetualmente nos postos, tornando-os mais adequados às atividades dos usuários. O fato de que as soluções propostas por uma equipe de Ergonomia podem proporcionar a melhoria da qualidade de vida dos funcionários, bem como da produtividade, é indiscutível. Entretanto, experiências vivenciadas até mesmo nas empresas tratadas neste artigo, indicam que as convencionais intervenções, quando executadas sem a participação efetiva de colaboradores da empresa, diversas vezes são deixadas de lado com o passar do tempo, quando as modificações já não constituem mais uma novidade.

Os trabalhos realizados nas empresas aqui tratadas geraram resultados bastante positivos, 
mesmo diante da existência de tantas peculiaridades. Na empresa A, o fato do comitê ser composto pelo staff da administração da empresa tornou-se um aspecto positivo, se levada em consideração a autonomia deste grupo na gestão dos recursos e das pessoas. As reuniões sistemáticas com os grupos geraram demandas que foram repassadas para o corpo operacional da fábrica de forma participativa e, a cada conclusão, as informações iam sendo repassadas para o GA3, a fim de que eles validassem e propusessem mudanças. Já na "Empresa B”, a autonomia dos funcionários é que pode ser considerada agente determinante na definição das estratégias de aplicação da metodologia sugerida. Este fator, acima de tudo, proporcionou o comprometimento direto dos técnicos e operadores de produção com o Programa de Ergonomia da empresa. Deste modo, pôde-se perceber com a formação de Comitês de Ergonomia em empresas com características bastante distintas, que é perfeitamente possível ajustar o método ergonômico à realidade de cada empresa, desde que se observem as particularidades, levando-se em consideração seus potenciais e limitações.

\begin{abstract}
This paper aims to introduce a comparative analysis of the beginning of an Ergonomics Programme in two companies in the Pernambuco State, Brazil. For both companies, it was used a participative ergonomics method which involved the creation of Ergonomics Committee in charge to introduce ergonomics actions in each company. This approach was responsible for involving the workers in the identification and solution of ergonomics problems. The results were extremely positive and had also showed that the method must be able to attend specific needs of each company.

Keywords: ergonomics programme; ergonomics committee; work analysis
\end{abstract}

\title{
Referências Bibliográficas
}

SILVEIRA, D. M. Programa de ergonomia nas organizações: reflexões e estratégias para implementação. Rio de Janeiro, Capes/Faperj, 2004.

SILVA, G. D. A., Estudo comparativo entre três metodologias de intervenção ergonomizadora: proposta preliminar para um modelo híbrido de intervenção. Programa de PósGraduação em Engenharia de Produção/Universidade Federal de Pernambuco. Dissertação Mestrado, 2005.

VIDAL, M.C.R. Ergonomia na Empresa - útil, prática e aplicada. 2ed. Rio de Janeiro, Ed. Virtual Científica, 2002. $276 \mathrm{p}$.

MORAES, A. de \& MONT'AlVÃO, C. Ergonomia: Conceitos e Aplicação / Anamaria de Moraes, Cláudia Mont'Alvão. Rio de Janeiro, Ed. 2AB, 2003.

HERSEY, P.. Psicologia para administradores: A teoria e as técnicas da literatura situacional / Paul Hersey, Kenneth H. Blanchard. São Paulo. EPU, 1986.

GUimarãeS, L. B. M. Macroergonomia. Apostila do $2^{\circ}$ Curso de Especialização em Ergonomia da Universidade Federal de Pernambuco. Recife, 2001.

HENDRICK H. Macroergonomics: introduction to work system design / Hal W. Hendrick ad Brian M. Kleiner. P.cm. In: HFES issues in human factors and ergonomics book series, volume 2, 2001.

\section{Dados completos dos autores}


Nome completo: Marcelo M. Soares

Filiação institucional: Universidade Federal de Pernambuco - UFP

Departamento: Departamento de Design

Função ou cargo ocupado: Professor Adjunto

Endereço: Av. Prof. Moraes Rego, sn - Cidade Universitáira

CEP: 50670-420 - Recife, PE - Brasil

Telefone: (81) 32718316

e-mail: marcelo2@link.com.br

Recebido para publicação em: 30/07/07

Aceito para publicação em: 22/08/07 